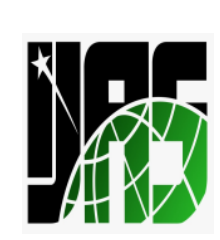

Indonesian Journal of Arabic Studies, Vol.3 Issue 1, May 2021

Avaliable online at:

http://www.syekhnurjati.ac.id/jurnal/index.php/ijas/index

DOI : 10.24235/ijas.v3i1.8168

Published by Departement of Arabic Language and Literature, Faculty

of Adab, IAIN Syekh Nurjati Cirebon, Indonesia

\title{
Problems of Teaching Arabic to Non-Native Speakers in Religious Schools in Sri Lanka
}

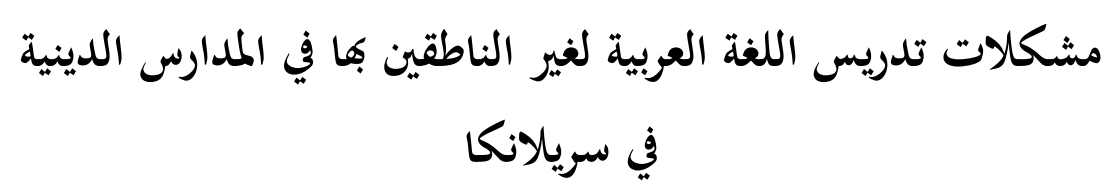

Mohamed Nafeel Mohamed Zawahir

nafeel.zawahir@arts.pdn.ac.lk

Department of Arabic and Islamic Studies, University of Peradeniya, Sri Lanka

• Received: 28.03.2021 • Accepted: 30.04.2021 • Publishedonline: 05.05.2021

Abstract: Sri Lanka is a non-Arab country which gives utmost priority for teaching Sinhalese, Tamil and English languages, a question arises on how the teaching activities can be performed according to the academic curricula and regulations, how Arabic language teaching books are composed, and how the religious schools can be supervised by non-governmental social entities, abiding by the principles of teaching while facing several challenges. This study strives to find the solutions for such issues. To conduct this research, the researcher has followed the descriptive and analytical approach, for which he has taken three long-standing religious colleges namely (Al-Bari Arabic College, Al-Ghafooriya Arabic College and Jamiathul Falah Arabic College) that have contributed to boom up the Arabic language in Sri Lanka and have been rendering this service for more than seventy five years. Also the researcher found that teaching methodologies of Arabic language have not been developed enough in Sri Lanka according to the modern era, although it is being taught in various fields and level at national universities, government and religious schools. These institutions follow the traditional curricula in teaching Arabic language. The process of teaching Arabic in Sri Lanka needs to unify the textbooks into a general academic curriculum, which will be suitable for the contemporary world inclusive of all fields of study that are implemented in the religious schools, in addition to appointing Arabic language teachers from Arab countries, planning and implementing projects in order to face the challenges that the Arabic language is going through in Sri Lanka, while 


\section{M.Z.M Nafeel}

encouraging them to teach the functional Arabic language rather than applying traditional memorizing teaching Methods and organizing teacher training.

Keywords: Teaching Arabic Language, Religious Schools, Tamil Language and Curriculum of Arabic Colleges.

الملحص:سريلانكا دولة غير عربية حيث إها تهتم اهتماماً كبيراً بتدريس اللغات السنغالية والتاميلية والإنجليزية فيبدو سؤال كيف يمكن القيام بالأعمال التدريسية وفق المناهج والقواعد

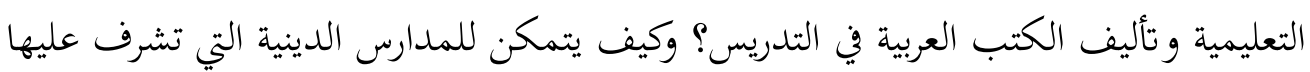

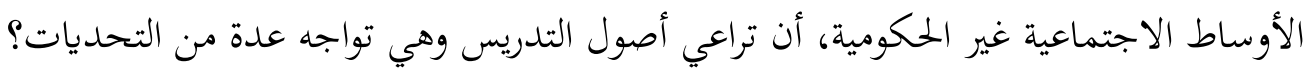

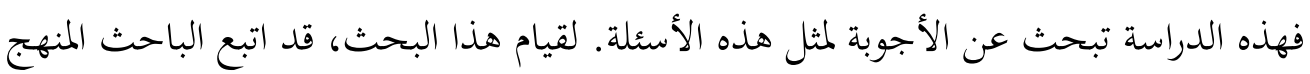
الوصفي التحليلي، كما أخذ المدارس الثلاث القديمة (مدرسة الباري ومدرسة الغفورية ومدرسة الفلاح) التي ساهمت لازدهار اللغة العربية في سريلانكا ومرّت في هذه الخدمة بأكثر من خمسة وسبعين سنة عينة الدراسة.وقد استنتج الباحث إلى أن تدريس اللغة العربية في سريلانكا لم يتطور

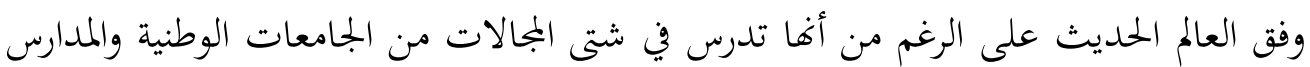

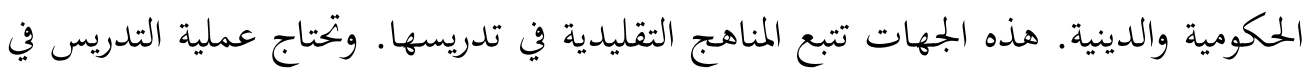
سريلانكا إلى توحيد المقررات الدراسية على مقرر دراسي عامّ يناسب العالم الحاضر حيث يستغرق جميع المجالات في المدارس الدينية كأها أهمّ الجهات فيه وتعيين المدرسين من الدول العربية لتدريسها وتخطيط المشروعات وتنفيذها لمواجهة التحديات التي تعانيها اللغة العربية في سريلانكا والحث على اللغة الوظائفية بخلاف تدريسها بطريقة التحفيظ وتدريب المدرسين في مجال التعليم وتدريسها. كلمات دلالية: تدريس اللغة العربية، المدارس الدينية، اللغة التاملية، مقرر المدارس العربية.

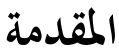

اللغة هي ما يخرجه الفم من الأصوات المتتابعة التي تنشأ صورة معينة فتصدر عنها علامة المعنى المعينة ـ واللغة العربية من أهم الوسائل الاتصالية التي تستعملها البشرية. ونعني بوسائل 


\section{M.Z.M Nafeel}

الاتصال وإعلام غيرنا أو إشعارهم بآرائنا وشعورنا وأخبارنا بأسلوب سهل كما يعرف في القواميس ويستخدم لوسائل الاتصال أيضا الإشارات العلامات والألوان والكالام والكتابة وأمثالها من الوسائل ويمكننا القول إن هذه المعاني كلها تعد لغة ولكنها لا تعني إلا استعمال الكتابة والكلام. إن اللغة تشعر المعنى، والمعنى يساعد للحياة الجماعية حيث يعرف بعضهم البعض وتعتبر اللغة أساسا لحضارات الناس وحياهم وتقاليدهم وفنوهم. ومن ثم تُقارن حياة الفرد بحياة المجتمع. ومن خلال اللغة يمكننا أن نشغل الآخرين بالأوامر وكذلك نستفيد بها لنقل المعلومات والآراء من مكان إلى مكان ومن زمان إلى آخر خلال فتره وجيزة. هناك اختلافات في اللغات بعضها يحتفظ بالصفات والمميزات الأصلية عبر القرون يعني هناك لغات ضعيفة ولغات قوية. مثلا اللغة العربية من اللغات القومية. وكذلك هناك لغات حية ولغات ميتة. وفي اللغة نرى التوقيفيات .من بين هذه اللغات، أما اللغة العربية فهي إحدى اللغات السامية. انشعبت هي وهن من أرومة واحدة نبتت في أرض واحدة. فلما خرج الساميون من مهدهم لتكاثر عددهم، اختلف لغتهم الأولى بالاشتقاق والاختلاط. وزاد هذا الاختلاف انقطاع الصلة و تأثير البيئة وتراخي الزمن حتى أصبحت كل لهجة منها لغة مستقلة. اللغة العربية هي لغة القرآن الكريم نزل بها دستور الإسلام وكتاب الله العزيز، قال تعالى "انا جعلناه قرآنا عربيا لعلكم تعقلون" (سورة الزخرف: الآية: 3). وملا كانت اللغه العربية لغة القرآن وسنة الرسول عليه الصلاة السلام، وقد ارتبطت بالإسلام والمسلمين. بهذا الوصف ان اللغة العربية هي لغة الدينية للمسلمين في جميع انحاء الأرض سواء كانوا يتكلمون أم لا. فالعربية اذن اداة الحضارة والثقافة الإسلامية العربية العريقة . إن اللغة العربية بتراثها الادبي الضخم تعتبر احدى اللغات العظيمة في العالم. فمنذ بزوغ فجر الإسلام في لغة الإسلام والمسلمين. فبها نزل القرآن الكريم دستور المسلمين. و.بها تحدث خاتم النبيين والمرسلين. ثم اها من أقدم اللغات الحية في العالم. لم يعترها كثير من التغيير والتبديل. ويتحدثها أكثر من 467 مليون نسمة .

وليس هناك أدنى شك في أن حياة اللغة العربية عبر العصور تعود أساسا إلى الإسالم حيويته. ولأن اللغة العربية لغة القرآن الكريم فإِا ارتبطت بالإسلام ارتباطا وثيقا. فهي اللغة 


\section{M.Z.M Nafeel}

الدينية للمسلمين في جميع أنحاء العالم سواء أكانوا من العرب أم العجم. فاللغة العبية لغة العبادة لكل المسلمين. هي انتشرت وحدها بقوها الخاصة بقوة الإسلام وقوة القرآن. وبهذا استطاعت أن تكون لغة عالمية. قال رسول الله صلى الله عليه وسلم "خيركم من تعلم القرآن وعلمه"-A1) Bukhārī, 1987 No.4739) على كل مسلم أن يتعلمها إلى درجة أداء العبادات والشعائر الدينية بها. والمسلمون يتلون القرآن الكريم باللغة العربية. فلا يجوز استخدام ترجمة بلغة أخرى بدلا عن الأصل العربي . ومحا لا شك فيه إن الإسلام دين حضارة حية ثقافية واقعية وتعتمد حضارته على القرآن الكريم والحديث الشريف وعمل أصحاب الرسول صلوات الله وسلامه عليهم وتاريخ اعلام الإسلام. انما هي منابع رشد لجميع المسلمين. فمن يريد أن يطلع على مبادى الإسلام وحضارته مسائل الثقافة فلابد أن تكون لديه معرفة باللغة العربية. لأن مصادر الشريعة الإسالامية ومسائلها المختلفة معظمها مكتوبة مشروحة باللغة العربية. فمن هذه الناحية فان المسلمين منهم من يرغبون فن أن يطلعوا على مبادى الدين ويطبقوها في حياتم اليومية ويرشدوا المسلمين إلى صراط الله المستقيم. ولذلك يقول عمر رضي الله عنه، "تعلموا العربية فإغا من دينكم" "Al-Batili, ).

اللغة العربية ذات طابع ديني وصبغته صبغة ربانية، "صبغة الله ومن أحسن من الله صبغة" (سورة البقرة: الآية: 138) والحق أن هذه الصفة تكاد تنفرد بها العربية التي أصبحت بهذه المثابة لغة مقدسة ذات قيمة عالية في الميزان الإسلامي عند المسلمين. و لا عجب ولا دهشة حين ندرك أن كثيرا من الأمم الإسلامية غير العربية تعتبر بالحروف العربية ليس تعصبا للعربية بل عقيدة ودينا.

وعلى هذا الضوء يمكن أن نقول إنه منذ القرن السابع الميلادي ظهرت العناية في تعلم العربية لدى المسلمين. ليس فقط من جانب العرب بل أيضاً من غير العرب وعلى هذا كان الدين الاسلامي هو العامل الرئيسي والدافع لكثير من الناس المى تعلم العربية وذلك لينهجوا فه من سبقهم. 


\section{M.Z.M Nafeel}

التدريس فن من فنون التواصل والتطوير ومهنة مهمة يلزم فاعلها بالتحلي بواجباتما مع

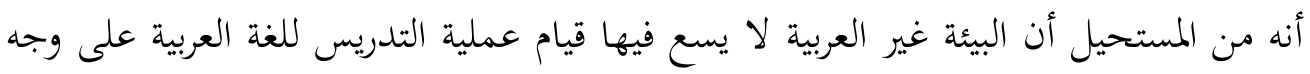

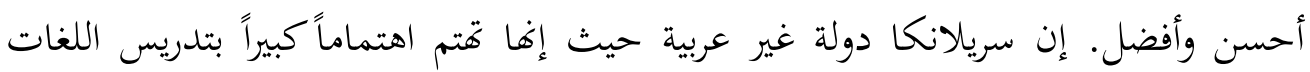
السنغالية والتاميلية والإنجليزية فيبدو سؤال كيف يمكن القيام بالأعمال التدريسية وفق المناهج والقواعد التعليمية وتأليف الكتب العربية في التدريس؟ وكيف يتمكن للمدارس الدينية التي تشرف عليها الأوساط الاجتماعية غير الحكومية، أن تراعي أصول التدريس وهي تواجه عدة ونديف

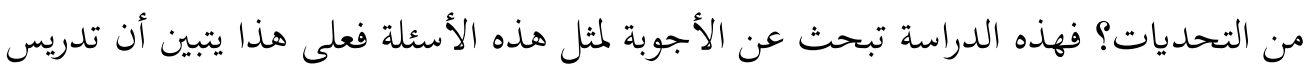
اللغة العربية في سريلانكا، كان عملا ضعيفا، ينبغي الاهتمام على المدارس بتعليمها تعليما صحيحا . n محن

$$
\text { فتسعى هذه الدراسة لتحقيق الأهداف التالية: }
$$$$
\text { 1. إبراز أهمية اللغة العربية وتاريخ انتشارها في سريلانكا. }
$$$$
\text { 2. التعرف على المدارس الدينية في سريلانكا }
$$

3. إظهار المشكلات التي غالباً ما تواجه المدارس الدينية عند القيام بالأنشطة التدريسية

$$
\text { للناطقين بغير العربية. }
$$

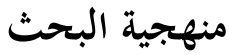

تققيقاً لهذه الأهداف، قد اتبع الباحث المنهج الوصفي التحليلي، كما أخذ المدارس ثلاث مدارس قديمة كعينة بحث وهي مدرسة الباري ، ومدرسة الغفورية ، ومدرسة الفلاح. ساهمت المدارس الثلاث ولعبت دورًا كبيرًا في تطوير اللغة العربية في سريلانكا وهي مدارس دينية تُدرِّس اللغة العربية للناطقين بغيرها و مرّت في هذه الخدمة بأكثر من خمسة وسبعين سنة عينة الدراسة. وقد أعدّ الباحث أسئلة استطلاعية على بعض مدرسي اللغة العربية المرشحين من المدارس المختارة عن طريق المقابلة لاكتشاف المشكلات في تدريس اللغة العربية وأساليبها ثم قام بتحليلها تحليلا وصفيا حيث الاستقراء العلمي والطريقة المكتبية لجمع المعلومات الأكاديمية والثقافية الإضافية. 
"عرفت جزيرة سريلانكا قديماً باسم "سِيلان" عند الإنجليز . وأما العرب فعرفت عندهم

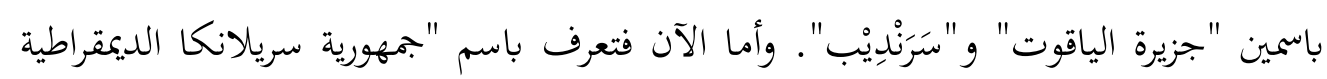

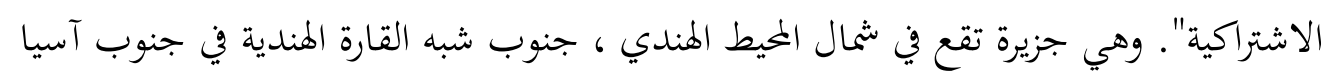

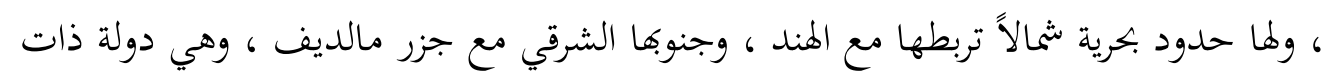
إرث حضاري عريق يمتد عبر ثلاثة آلاف سنة، وموقعها الاستراتيجي في متلقى الطرق البحرية الرئيسية الرابطة بين غرب آسيا وجنوب شرق آسيا". Hosein, 2007)

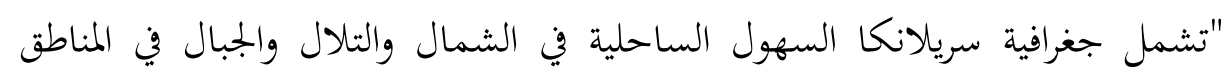
الداخلية. نظام الحكومة جمهورية ؛ والرئيس يترأس الدولة بالتنسيق مع مجلس الوزراء والبرلمان.

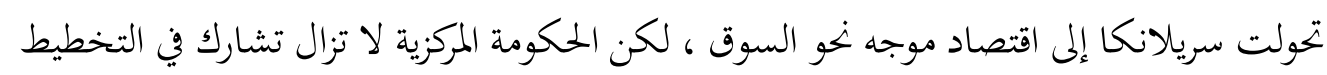

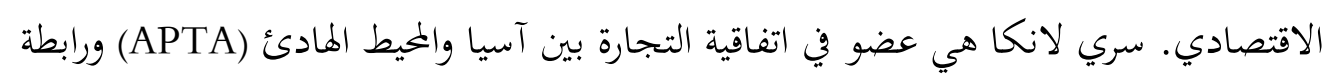
جنوب آسيا للتعاون الإقليمي (Maḥyuddīn, 2019).(SAARC)

\section{2. انتشار اللغة العربية في سريلانكا}

تحكم على نشر اللغات في العالم ظروف مختلفة منها ما هو روحي أو سياسي أو

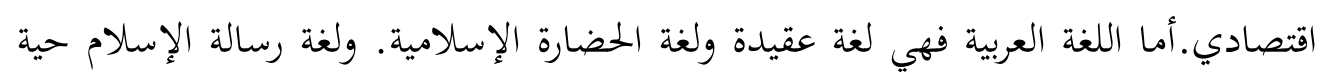
خالدة في القرآن الكريم المتعبد بكلمات وهي ودعاء العقيدة الإسلامية مدى الدهر تمثم هو أداة

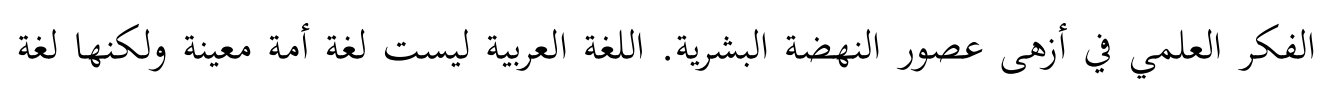
العالم الاسلامي كله. فهي لغة العبادة الدينية للمسلمين يؤدون بها شعائرهم الدينية حيث كانوا.

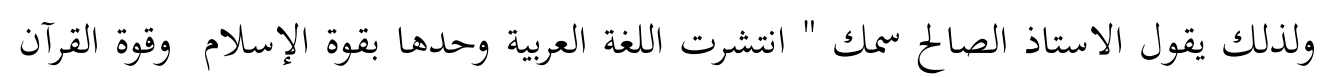
وبهذه كله استطاعت أن تكون لغة عالمية(Samak, 1979)." وقد علمنا بما سبق ذكره أن لانتشار اللغة العربية علاقة ثابتة بالثقافة الإسلامية وحضارتها

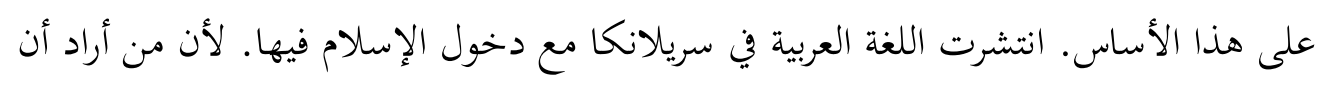




\section{M.Z.M Nafeel}

يفهم الاسلام ويدرك حقيقته لابد من أن يفهم القرآن الكريم والأحاديث الشريفة. فلابد من معرفة الحروف العربية لكي يتحقق هذا الهدف الإسلامي.

فقد بدأت اللغة العربية يضيئ نورها من المساجد حيث إها هي المركز الأول لتعليم اللغة

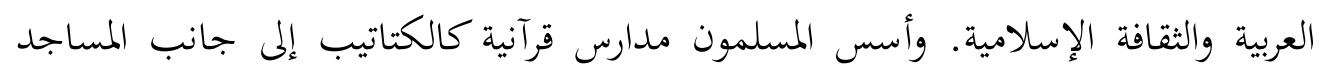

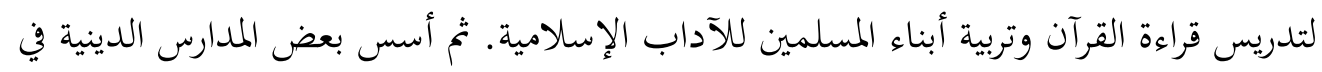
قرى المسلمين في القرن التاسع عشر الميلادي تمدف إلى تزويد المسلمين بالعلوم الدينيةعن طريق برديق

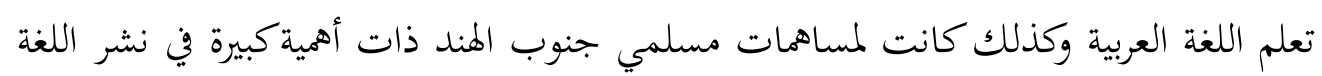
العربية في سريلانكا.

وقد بدأت مرحلة جديدة في هضة اللغة وتطورها في سريلانكا بعد وصول عرابي باشا

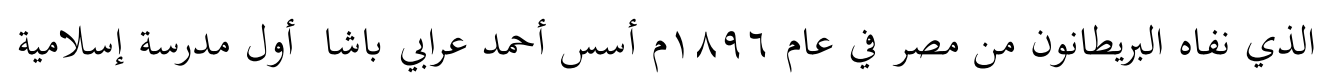
في كولومبو العاصمة وهي مدرسة "الزاهرة"وما زالت هذه المدرسة حتى الآن تواصل تعليم أبناء المسلمين التعليم العالي. وهلا دور فعال وإنجازات عظيمة في نشر اللغة العربية والثقافة الإسلامية

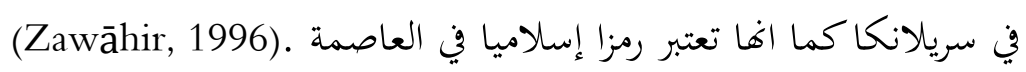

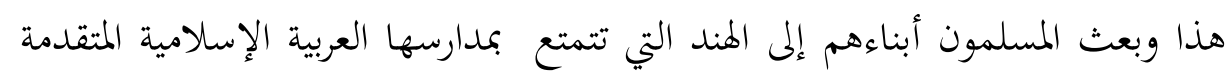
فواصل هؤلاء الطلاب التعليم العربي الإسلامي ورجعوا المى سرنديب حاملين الرسالة الإسلامية

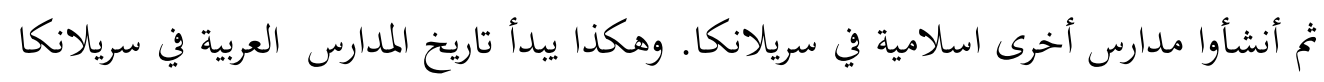

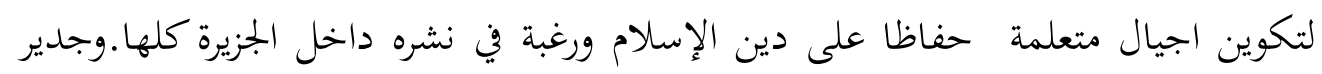
بالذكر أن العالم الكبير "سدى لبي" أيضا كان سببا في إنشاء مدرسة "الزاهرة" وتطورها مجال

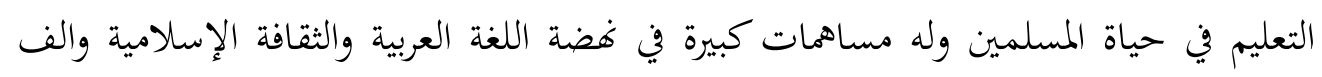
كتابا يتعلق بتعليم اللغة العربية ومن الكتب التي الفها العلامة "سدى لبي" خاصة لتعليم اللغة العربية.

$$
\text { (1) تحفة النحو (r) الهداية القاسمية إ) أصول القراءة العربية. }
$$

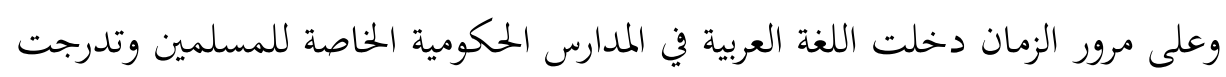

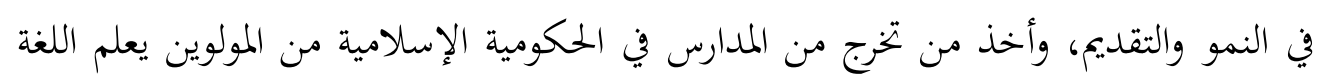


العربية كمادة في المدارس الحكومية، ثم ترقت اللغة العربية حتى انشئ لها قسم مستقل في بعض

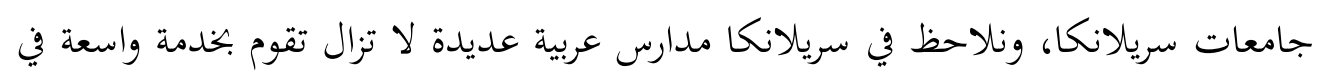
نشر اللغة العربية والثقافة الإسلامية. (Zawāhir, 1996)

\section{3. دور المدارس الدينية نحو اللغة العربية}

تلبيةً لاحتياجات المجتمع الإسلامي الدينية في هذه الدولة، سافر كثير من الشباب المسلمين إلى الدول الخارجية من الهند وباكستان ومصر وسائر الدول العربية والإسلامية في طلب العلم الشرعي وتعلم اللغة العربية. "لم تبدأ المدارس العربية في سريلانكا قبل 150 سنة.

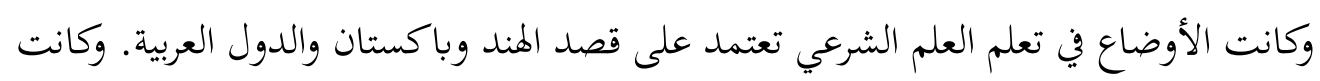
هناك الضغوط الاقتصادية والشدائد السفرية وإمكانيات الإقامة والمشكلات في تلقي التئي التأشيرة

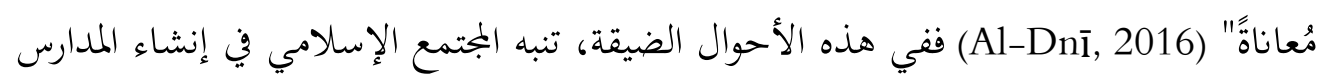

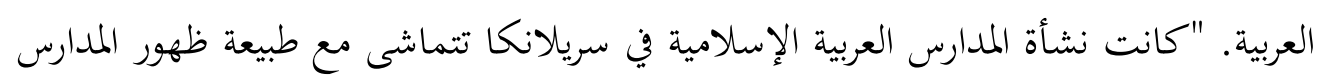

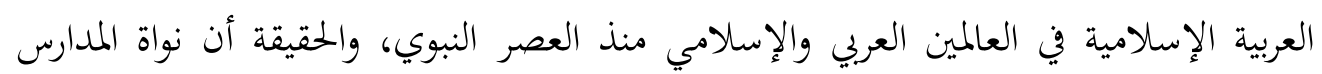
العربية الإسلامية بدأت بالحلقات التي عقدت في المساجد لغرض تعليم كتاب الله الكريم، فالعلوم

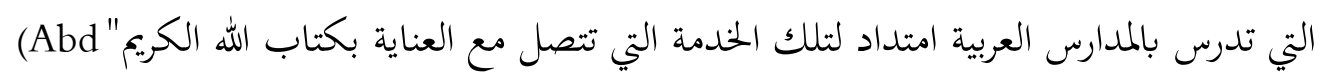
Al-Sattār, 2015)

قد لعبت هذه المدارس العربية دوراً مهما في نشر اللغة العربية وفنوها وآدابها في أرجاء

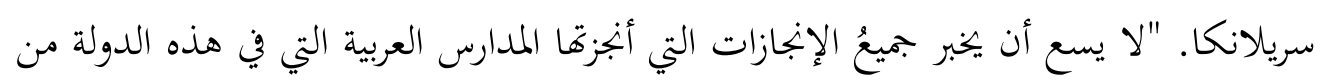

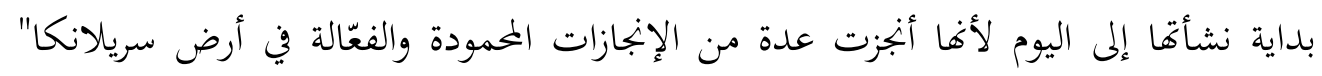
حيث قامت بصحوة إسلامية في فترة أقلّ من ألف سنة أدّت المسلمين (Abd Al-Sattār, 2015)

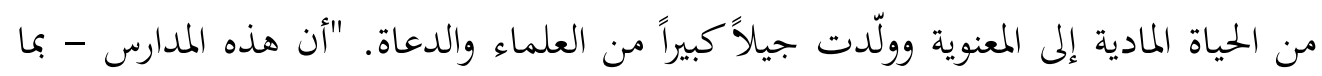
هيئ لها من أسباب - أصبحت شجرة طيبة أصلها ثابت وفرعها في السماء تؤتى أكلها كل

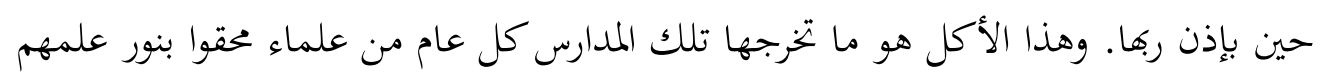

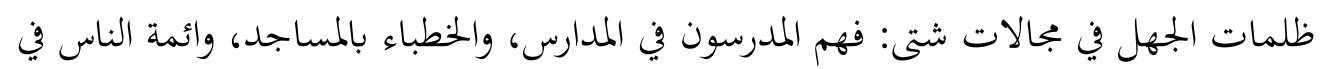


M.Z.M Nafeel

الصلاة، ومديرو المدارس، ومدرسو المدارس الحكومية. وهكذا كلما يممت وجهك وجدت هؤلاء

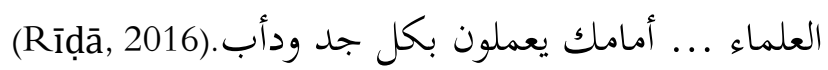
ومن أهمها، المدارس الثلاث التي تمّ أخذها عينة الدراسة وهي؛ بعلى وداء

1. مدرسة الباري العربية: ابتدأت هذه المدرسة بالعلامة بالعالم العروس في مسجد البخاري

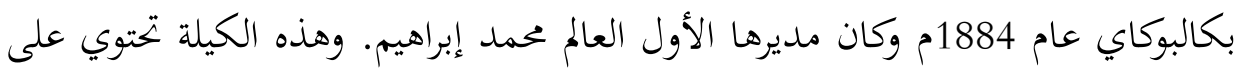
قسم الشريعة وتحفيظ القرآن الكريم مع قسمي الحديث العالي والفقه العالي وكذا يُعد وإيد الطلاب للامتحانين الحكومين العالم والأحدية (Mahyyuddīn, 2019) 2. الكلية الغفورية العربية للدراسات الإسلامية: بدأها الحاج عبد الغفور في مقره الذي وقفه لله تعالى عام 1350هـ الموافق لعام 1931م. وكان مديرها الأول العالم العلامة عليار مركار مع ثلاثة من المدرسين. وهذه الكيلة تحتوي على قسم الشريعة وتحفيظ القرآن الكريم مع إعداد الطلاب للامتحانين الحكومين المتوسط والثانوي مع الاختبارين العالم والأحدية (Maḥyuddīn, 2019) 3. جامعة الفلاح العربية التي تقع في مدينة كاتانكودي بشرق سريلانكا. وهي التي"بدأها

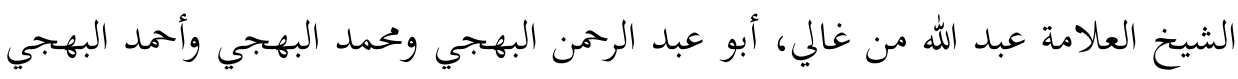

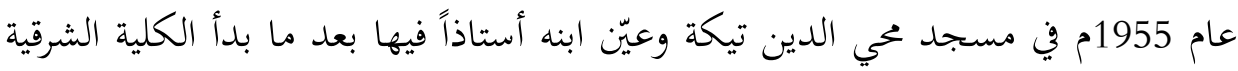
عام 1954م في أدالاشيناي حينما هاجر إليها في آخر حياته. وبدأ بحلقة القرآن الكريم حيث تتواصل حتى الآن."هذه الجامعة كوّنت حتى الآن 404 مولوي فلاحي و 421 حافظ آنس

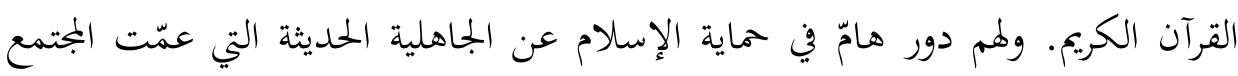
الإسلامي في هذه الدولة. (Maḥyuddīn, 2019)

\section{4. المشكلات التي تواجهها اللغة العربية في سريلانكا}

خلال البحث في هذه المدارس، قد توصل الباحث إلى أن اللغة العربية في سريلانكا تواجه المشكلات والصعوبات في تعلمها وتعليمها. يمكن تلخيصها كما يأتي: 1) تفشي الخوف من تعلم اللغة العربية وتعليمها.

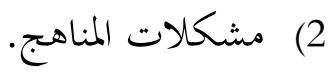


M.Z.M Nafeel

$$
\begin{aligned}
& \text { 3) مشكلات الكتب المدرسية. } \\
& \text { 4) مشكلات عدم توفير الأدوات التعليمية المساعدة. } \\
& \text { 5 مشكلات المعلم. } \\
& \text { 6) مشكالات التلميذ. }
\end{aligned}
$$

4. - 1. 1 تفشي الخوف على تعلم اللغة العربية وتعليمها

إن اللغة العربية قد لاقت تحديات شتى في تاريخها من الأيام القديمة إلى العصر الحديث. فأعداؤها ظهروا عليها افتراءات باطلة فمثلا ما وضع الفرس أحاديث من عندهم لذمّ اللغة العربية (Ali, " حيث جاء "إن الله إذا غضب أنزل الوحي بالعبية ، وإذا رضي أنزل الوحي بالفارسية Al-Quwaisy, \& Murad, 1999) تقسيمها إلى القسمين؛ الأول التحديات الداخلية مثل هجر هذه اللغة الفصحى واستبدال العاميات المحكية بها أو مزجها بالعاميات بدعوى التسهيل والتيسير، أو الاعتماد على اللغات الأجنبية بديالً عنها وغيرها. "إن الناظر في حال اللغة العربية اليوم في المجتمعات والبلاد العربية والإسلامية يشعر بألم عميق، وحسرة شديدة؛ لكوها لا تحظى بما تستحقه من احترام، وليست عندهم في المكان اللائق والموضع المناسب، ومؤلم جداً أن تكون هذه النظرة وذلك الموقف من أحباءها لا من أعدائها، إن أخطر ما يوجهه أبناء العبية ذلك العقوق والتنكر أو التجاهل وعدم المبالاة" (Ibrāhīm, 2017).

وأما الثاني فالتحديات الخارجية مثل مزاحمة اللغات الأخرى لما والغزو الفكري الوافد من الأمم الأخرى والعولمة التي تريد ابتلاع ثقافات الأمم والشعوب، والقضاء على هذا التنوع اللساني في العالم. وأعداءها يسعون لتحقيق آمالهم ضد هذه اللغة وحضارةتا وشعبها كما يقول الدكتور أحمد بن نعمان "فإنه من غير الطبيعي ألاّ تصادفها المشاكل وتعترض طريقها العوائق والمعوقات وتحوم حولها التشكيكات في قدرقا على القيام بدورها الحضاري الذي يجب أن تستمر في القيام به لتبقى حية ولا تتجاوزها الأحداث لتحيلها إلى متحف تاريخ اللغات... كما يرغب الأعداء في ذلك ويعملون كل ما في وسعهم لتحقيقه بكل الوسائل". (Nu’mān, 2008) 


\section{M.Z.M Nafeel}

"وكذا الأوضاع الراهنة تشتدّ ضد العربية ويقوم العنصريون بالدعوة ضدها لمنعها في (Maḥyuddīn, "الدولةولكن الحكومة لم تخضع لادعاءاتم. بل، الظروف تضيقت على العربية (2019حيث "أصدرت حكومة سريلانكا، الإثنين 10 يونيو/حزيران 2019، قراراً يخظر استخدام اللغة العربية في أسماء شوارع البلاد....و تأتي هذه الخطوة كردّ فعل لهجمات (يتهم أنه قامت حركة داعش بهذه الهجمات الانتحارية مستهدفة للكنائس والفنادق في سريلانكا في اليوم الواحد والعشرين لشهر إبريل لعام 2019م حيث تضرر حوالي ثمانيمائة من الرجال والنساء والصغار قتيلاً وجريجاً.) استهدفت كنائس وفنادق في سريلانكا بالتزامن مع احتفالات المسيحيين بعيد الفصح؛ وهو ما أسفر عن مقتل 253 شخصاً وأكثر من 500 جريح. وتبنى تنظيم داعش الإرهابي تلك الهجمات" (Arabicpost.net, 2019) هذه الهجمات ضاعفت الضغوط ضدّ اللغة العربية تعلماً وتعليماً.

\section{4. - 2. 2 المشكلات في المناهج}

المناهج هي إحدى الدعامات الهامة التي تبني عليها عملية التعليم للغة العبية والدراسات الإسلامية فالمناهج الدراسية في المدارس الدينية للغة العربية والعلوم الإسلامية تكون عادة مناهج اكاديمية تستمر لملدة ثمان سنوات وتقلد على الدراسة الإسلامية لكي يسهل على الدارسين التعرف على الإسلامي ومصدرية الأصلين القرآن والحديث وحتى يتمكن على ضوء ذلك من ممارسة الحياة الإسلامية ولكن هذه المناهج تقليدية مايزال الطلاب يواجهون الصعوبات العديدة بسسب ضعف المناهج فالسبب الرئيسي هو عدم توحيد المناهج للمدارس الدينية وعدم وجود التخطيط لما. وإن هذه المناهج التقليدية تضعف حماسة المتعلمين في مواصلة دراساتم وتبعدهم كل البعد عن المدارس الدينية فهذه هي الصعوبة الكبرى التي تعترض وتحد من نشاط تعليم اللغة العربية. ويف المدارس والمعاهد الإسلامية التابعة للحكومة تدرس اللغة العربية باللغة السريلنكية مع أها تعتبر واحدة بين المواد الأخرى المقررة.

وعلى ضوء ذلك تبين خلال ملاحظاتنا السابقة بأن المناهج المستعملة للغة العربية والعلوم الإسلامية في سريلانكا حالياً مناهج ضعيفة لاتواكب التطورات العبية والإسلامية. فإذن أن هذه المناهج في حاجة ملحة إلى التجديد والتغيير المناسب للحياة المعاصرة. يذكر صالح عبد 


\section{M.Z.M Nafeel}

العزيز " أنه من الواجب أن يكون المنهج الدراسي ملبيا لحاجات المجتمع فالتربية الحلديثة تنادي بأن تكون مناهج الدراسة ملائمة لحاجات الزمان والمكان وحاجات البيئة المحلية، فيجب أن يقوم المنهج على أساس هذه الحاجات بشكل يساعد المتعلم على اكتساب القدرة يعيش كفرد نافع في المجتمع وأن يحترم هذا المجتمع عن طريقة المساهمة في حل مشكاته والنهوض به" Abdul) Az̄̄z \& Abdul Mağīd, 1971) في المدارس العربية العديدة في سريلانكا رأى اها لا تزال تسير على نمط واحد منذ عشرات السنين على الرغم من أن هناك تعبيرات طرأت في المجتمع الإسلامي في العصر الحديث. إن هذه المدارس المسؤولون عنها في الواقع لا يشعرون بأن حياة الأمم والشعوب في تطور دائم وتغيير، فيجب أن يكون منهج الدراسة يخضع لهذا التغيير والتبديل ولكن فإن كثيرا من المسؤولين بذذه المدارس العربية الإسلامية لايوافقون على تغيير المنهج وتعديله وفق مطالب الحياة المعاصرة،هذه هي المشكلة المهمة التي تعانيها المدارس العربية في سريلانكا بالنسبة إلى المنهج.

\section{4. - 1. 3 مشكلات الكتب الملدرسية}

تعد الكتب المدرسية من أهم أدوات العملية التعليمية على أن الكتب المدرسية العاملة في كل المدارس الدينية العربية ماعدا بعض المدارس المهمة. وإن هذه الكتب المستعملة منذ القديم إلى اليوم تأتي عن طريق الدول العبية و من تلك الكتب المدرسية على سبيل المثال. (1) شرح ابن عقيل على ألفية ابن مالك.

$$
\text { (r) مطالعة السعودية (ثلاثه اجزاء). شرح ابن هشام ومقامات الحريري. }
$$$$
\text { ( ) البلاغة الواضحة لعلي الجازم ومصطفى أمين. }
$$

نرى مثل هذه الكتب القديمة المكتوبة كثير ما تحتوي على موضوعات محلية بحتة بعيدة عن أذهان التلاميذ في سريلانكا وهي موضوعات جافة لعدم اتصالما بجياتم وظروف بلادهم والبيئة المحيطة بهم. فالموضوعات مثل الصحراء واشجار النخيل وما إلى ذلك من الموضوعات غير الحية في الحياة السريلانكية. 


\section{M.Z.M Nafeel}

والطلابيواجهون المشكلات بوصول تلك الكتب لأن الكتبالموجودة غير كافية بالنسبة لعدد الطلاب في الصفوف فالتلاميذ ينقلون الدرس بالكتابة تم يدرسوفا كما أفم غير مستطيعين للحصول عليها لارتفاع ثننها وعدم وجودها في مكتبات سريلانكا.

\section{4 - 5 4. 4 مشكلات عدم توفير المساعدة التمويلية}

إن المعلمين والمتعلمين للغة العربية في سريلانكا يواجهون صعوبات كثيرة في التعليم والتعلم فلابد من معرفة أن بلاد سريلانكا هي دولة غير إسلامية لا تهتم بتنمية اللغة العربية ولاتعطيها

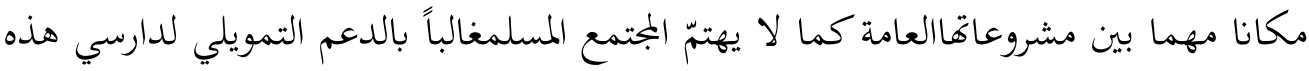
اللغة ومدرسيها.

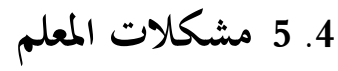

عدم توفر المعلمين المختصين في تدريس العربية والعلوم الإسلامية ومن المشكلات المهمة التي واجهها تعليم اللغة العربية هي عدم توفير المعلمين المختصين في هذا الحقل. ومما يجدير بالذكر بالملاحظة أن سريلانكا ليس فيها معاهد خاصة لتدريس وتخصيص المعلمين في تعليم اللغة العربية وكذا أن المعلم هو الأساس الذي يهيئ الأوضاع المناسبة لكي يتعلم التلميذُ وهو المسؤول لإرسال رسالة أو فكرة وإيصالها إلى أذهان التلاميذ.

فإذن إعداد المعلم وتخصيصه ركن عام جدا في تطوير العملية التعليمية بيد أن أغلبية المعلمين لم يتوفر لهم تخصص وإعداد لغوي كاف. والطريقة التي يتبعوفا في تعليم العربية هي تكاد تكون طريقة واحدة في جميع مراكز التعليم وهي طريقة الترجمة والقواعد.فالمعلم يترجم النص العربي

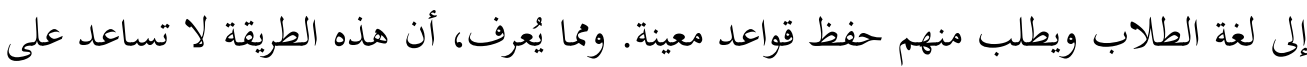
تنمية المهارات اللغوية لدى الطلاب ولاتمكنهممن استعمال اللغة كوسيلة اتصال حية. ومعلمو العربية لايزالون يواجهون مشكلة كبرى عند الكتابة والمحادثة باللغة العربية الفصحى المعاصرة. 4. - n 6 مشكلات التلميذ 


\section{M.Z.M Nafeel}

نجد دارسي العربية في عملية تعليم اللغة العربية والعلوم الإسلامية في المدارس الدينية العربية أقل حماسة وذلكلأسباب مختلفة فمنها ما يأتي: (1) عدم وجود التسهيلات والتجهيزات المناسبة و قلة الإمكانات المدرسية. (r) سوء معاملات الحكومة مع المدارس الدينية العربية في اللغة العربية. (r) الظروف الاجتماعية لا تشجع على التعليم في المدارس الدينية العربية.

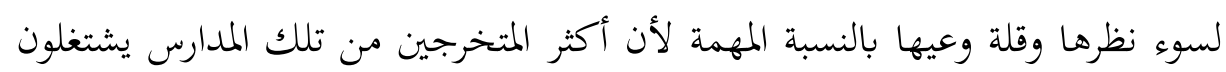

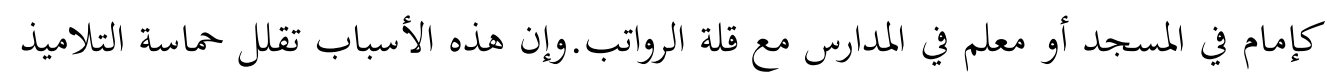

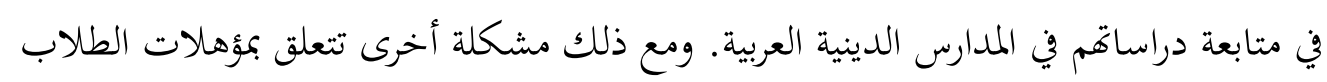
الذين يلتحقون بالمدارس العربية لا توجد لديهم خبرات حتى في لغتهم الأمّ التاميلية.

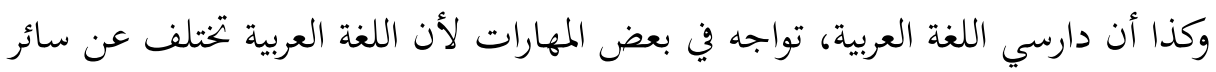
اللغات في سريلانكا حيث جانبي الصوت والكتابة وهذه الاختلافات تمثل صعوبة لدارسها. أما

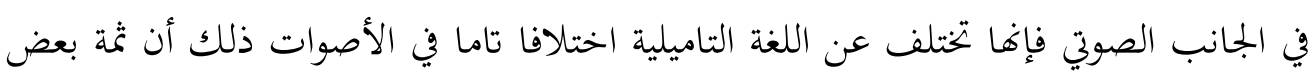
الأصوات العربية غير موجودة في اللغة التاميلية ولذلك أن كثيرا من الدارسين وغيرهم من المسلمين عامة يخطؤون في نطق بعض الحروف كما في نطق الزاء والذال والثاء والسين. الأصوات التالية الزاء والغاء وغيرها لاتوجد في اللغة التاملية. وأما في الجانب الكتابي فتكتب العربية من اليمين إلى اليسار وذلك أيضا صعوبة لدارسي اللغة العربية.

\section{الخاصة والتوصيات}

يبدو ممّا درسنا أن نشأة اللغة العربية في سريلانكا لم يحدث بمكر وخيانة وليس هناك أية

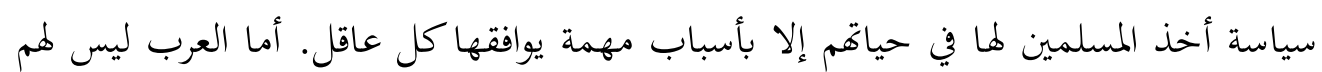

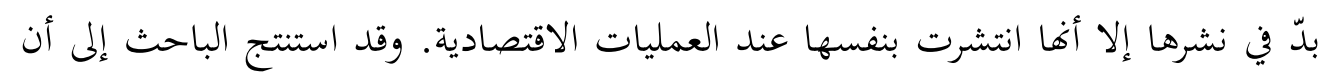

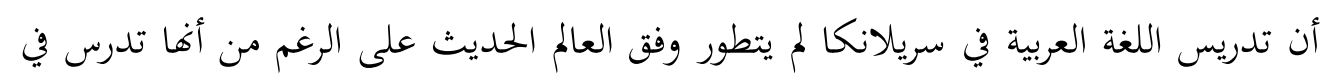

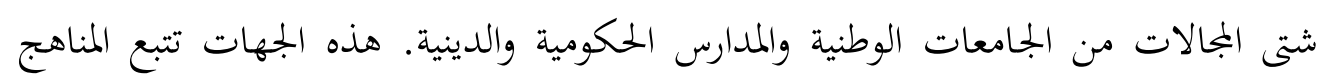
التقليدية في تدريسها. وعملية التدريس في سريلانكا تحتاج إلى توحيد المقررات الدراسية على سلى 


\section{M.Z.M Nafeel}

مقرر دراسي عامّ يناسب العالم الحاضر حيث يستغرق جميع المجالات في المدارس الدينية كأها

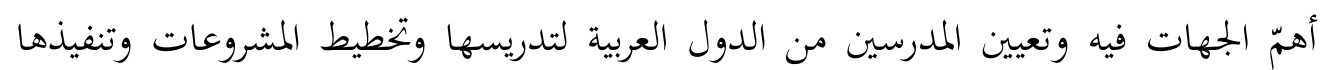
لمواجهة التحديات التي تعانيها اللغة العربية في سريلانكا والحث على اللغة الوظائفية خلاف تدريسها بطريقة التحفيظ وتدريب المدرسين في مجال التعليم وتدريسها. فتوصي هذه الدراسة، التنفيذ بالاقتراحات الأتية لتحسين تعليم اللغة العربية في سريلانكا:

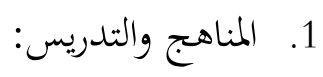

من الواجب على المدارس العربية الإسلامية في سريلانكا اختيار المنهج الملائم المتكامل والطريقة المناسبة لتعليم اللغة العربية في سريلانكا فإن طريقة التدريس المتبعة الآن هي طريقة الترجمة والقواعد يرى الباحث أن تستبدل هذه الطريقة التقليدية بالطريقة السمعية

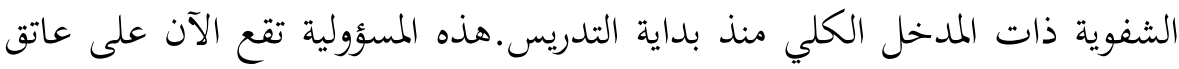
إدارة شؤون المسلمين والثقافة الإسلامية يمكن لها العمل على إجراء دراسات تقويمية

$$
\begin{aligned}
\text { 2. } \\
\text { إعلاهدج تعليم اللغة العربية. }
\end{aligned}
$$

المدارس العربية الإسلامية وغيرها من مؤسسات تعليم اللغة العربية في حاجة ماسة الى تدريب هؤلاء المعلمين تدريبا خاصا. لأن تعليم اللغة العربية تحتاج إلى خبرات معينة و

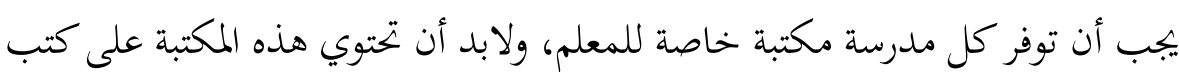

$$
\text { 3. خلع صعوبات الطلاب : تليها المعلم. }
$$

إن الدارسين في المدارس التعليمية للعربية في سريلانكا لابد أن توزع عليهم الكتب المقررة

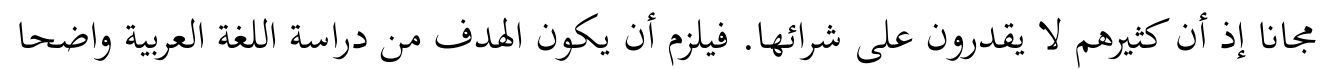

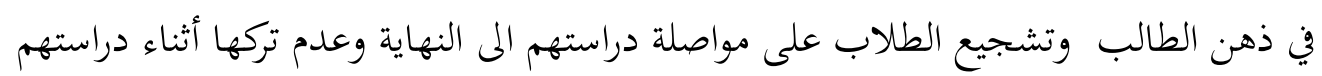

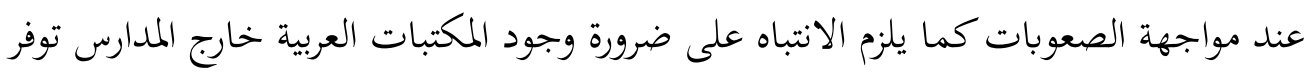
للطلاب العربية للاطلاع على الكتب. 


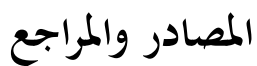

Abd Al-Sattār, K. A. A.-R. (2015). Wūẹ 'u Al-lug̀ah al-'Arabiyyah Bi AlMadāris Al-'Arabiyyah Al-Islāmìyyah Fì Srìlānkā. Sudan University of Science and Technology.

Abdul Azīz, S., \& Abdul Mağ ìd, A.-A. (1971). Al-Tarbiyyä̈ Wa Turuq Al-Tadrìs. Cairo: Dār Al-Ma' ārif.

Al-Batili, A. bin A. (2006). Al-' Aḥ ādīt wāl' āt àr Al-Wāridä̈ fi Faḍ l AlLugiä Al-'Arabìyä̈ Wa dam al-Laḥan: Riwāyä̈ Wa Dirāyä̈. Riyadh: Kunuz Isbiliya.

Al-Bukhārī, M. I. I. A. A. (1987). Ș ạ̣ ịh Al-Bukhārī. Beirut: Dār Ibn Katsīr al-Yamāmah.

Al-Dnī, M. (2016). Ru'yä̈ Naqdiyä̈ 'An Al-Madāris Wa Idārātihā. In Arb'ūn kullìyä̈ Arbiyyä̈ qāmat Bi Al-'Amāl Al-ha airiyyä̈ mund u arba'ä̈ 'Uqūd. Saintamarudu: Al-Mağ ma' Al-Islāmī lil hِ idmāt Alh

Ali, A. H., Al-Quwaisy, I., \& Murad, H. M. (1999). Maūsū'ä̈ Al-

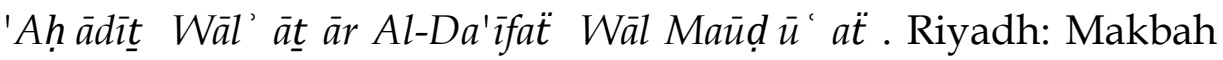
Al-Maarif.

Arabicpost.net. (2019). Srīlānkā Tafraḍ Quyūdā 'Ala al-Lugaä Al'Arabiyyä̈, Wa Maṭ ālib Bi Al-Taḥ qīq Fī «Maz ālim» AlMuslimīn. Retrieved 20 February 2021, from Arabicpost.net website: https:/ / arabicpost.net/ سريلانكا_تفرض-قيوداً_على_اللغة_العربي 10/06/2019/

Ḥosein, A. (2007). Sarnudub Dirāsä̈ Indulūğ iä̈ 'An muslimī Srìlānkā biAl-luǵä̈ Al-inğ lìzìä̈ . Kolombo: Maktabah Kolombo. 
M.Z.M Nafeel

Ibrāhīm, M. D. H. (2017). Al-lugä̈ Al-`Arbīyyä̈ wa Al-Atah diyāt AlMu' āṣ irẗ (Ast ār Wa Mutaṭ alibāt). Adhakira, 5(2), 315-331.

Maḥ yuddīn, M. H. Z. (2019). Manāhiğ Tadrīs al-lugiä̈ al-'Arbï̈ Lināt qīn Biğairihā. Bharathidasan University.

Nu'mān, A. (2008). Mustaqabal Al-lugiä̈ Al-'Arbiyyä̈ Baina Muḥ ābarabä̈ Al-'A'dā' Wa Irādä̈ Al-Samā'. Alger: Dar El Oumma. Rīẹā, A. A. R. (2016). Al-Madāris al-'Arbiyyä̈ Fī Srīlānkā Baīna alWāqi' Wā Al-ḥ ayāl. In Arb'ūn kullìyä̈ Arbiyyä̈ qāmat Bi Al-'Amāl Al-haairiyyä̈ mund u arba'ä̈ 'Uqūd. Saintamarudu: Al-Mağ ma' Al-Islāmī lil hِ idmāt Al-ḥ īariyyä̈ .

Samak, M. S. (1979). Fì Al-tadrīb Li Tarbiyah al-Lugawiyah. Cairo: The Anglo Egyptian Bookshop.

Zawāhir, M. N. M. (1996). Al-lug̉ah al-' Arabiyah fì Srīlānkā. Sri Langka: University of Peradeniya. 
M.Z.M Nafeel

This Page Is Intentionally Left Blank

تركت هذه الصفحة فارغة عمدا

'Halaman Ini Sengaja Dikosongkan' 